\title{
Accessibility Indices: A Connection to Residential Land Prices and Location Choices
}

\author{
Issam M. Srour \\ Graduate Student Researcher, Department of Civil Engineering, The University of Texas at Austin \\ ECJ B120B, Austin, Texas 78712, \\ Tel: (512) 232-6599 \\ Email: isrour@mail.utexas.edu \\ Kara M. Kockelman \\ (Corresponding Author) \\ Clare Boothe Luce Assistant Professor of Civil Engineering \\ The University of Texas at Austin ECJ 6.904, Austin, Texas 78712, \\ Tel: (512) 471-4379 \\ FAX: (512) 475-8744 \\ Email: kkockelm@mail.utexas.edu \\ Travis P. Dunn \\ Undergraduate Student Researcher, Department of Civil Engineering \\ The University of Texas at Austin \\ ECJ B120B, Austin, Texas 78712, \\ Tel: (512) 232-6599 \\ Email: tdunn@mail.utexas.edu
}

The following paper is a pre-print and the final publication can be found in

Transportation Research Record No. 1805: 25-34, December 2002.

Presented at the 81st Annual Meeting of the Transportation Research Board,

January 2002

\begin{abstract}
Specifications of accessibility indices range from simple minimum travel-time indices, to measures of cumulative opportunities within specified distance or time thresholds, to maximum utility measures. This paper presents models relating a variety of general accessibility indices for the Dallas-Fort Worth region of Texas to property valuations for single-family dwelling units and commercial units, and to household residential location choices.

Hedonic models are used to assess the importance of access on property valuations, while controlling for improvement attributes and parcel size. Multinomial logit models are used to derive logsum measures of accessibility as well as to assess the impact of access on location choices, while controlling for household demographics. Three functional specifications of access measures were used. Job accessibility (a proxy for work and other opportunities) was estimated to positively impact residential land values, in statistically and economically significant ways, suggesting - as hypothesized here - that land rents track property owners' assessments of accessibility, while other, common accessibility measures do not perform as well. After controlling for this measure, access to parkspace (a proxy for availability of outdoor recreational activities) and access to retail jobs (a proxy for shopping opportunities) were not valued in the land market. Distances to regional CBDs and household heads' workplace locations also played important roles in location predictions, often in the presence of the more general access measures.
\end{abstract}


Residential location-choice model results suggested which indices are better measures of accessibility. Different functional specifications appeared useful here. Cumulative opportunities access measures were most helpful in predicting residence location, but differences in predictive power were relatively small.

\section{Key Words:}

Accessibility, Property Valuation, Hedonic Models, Location Choice Models, Logsum, Land Residuals

\section{INTRODUCTION}

Land pricing and location choice models have traditionally been examined as distinct problems (e.g., Sermons and Seredich 2001, Kockelman 1997, Voith 1991, McMillan et al. 1980, and Lerman 1977). However, these are intimately related through the interaction of urban land markets, and an examination of accessibility indices relies on both topics here. Ideally, the accessibility of a location is a measure of how well transportation networks interact with land use attributes to satisfy household, business, or others' preferences. Specifications of accessibility indices have ranged substantially: from simple minimum travel-time indices (e.g., Leake and Huzayyin 1979), to measures of cumulative opportunities within specified distance or time thresholds (e.g., Wachs and Kumagi 1973), to maximum utility measures (e.g., Niemeier 1997). From the perspective of land markets, rents paid to purchase land may make great sense as a measure of access. The value of access is capitalized into the land value and access is measured in market participants' willingness to pay. Essentially, this view expects that accessibility measures may be inferred from land prices. This is the approach taken here.

This study develops two general types of models: one for residential property valuation and one for destination and residential location choice. After discussing related works, the paper describes the model structures and data sets used. The subsequent sections discuss results and conclusions.

\section{LITERATURE REVIEW}

There is extensive literature devoted to the valuation of land as tied to travel costs, access to market centers, and network improvements. For example, Mohring (1961) examined the effect of highway improvements on land values across a region, using a small data sample in the Seattle area.

More than a decade later, Anas (1979) simulated how changes in transportation policy, income, employment, and housing spatial distribution affect land values.

In a similar investigation between a CBD and suburban residential regions, Voith (1991) found the premiums based on accessibility in areas with good commuter service to be $6.4 \%$ of average house values.

Taking a different approach, McMillan et al. (1980), attempted to estimate homeowners' willingness to pay for public "goods," specifically quiet (in this case freedom from aircraft noise). After controlling for a variety of structural characteristics (e.g., number of bathrooms, masonry exterior and home age), and while assuming that all household decision-makers have identical "homothetic" preferences for such attributes, they estimated - as expected - a significantly positive effect for the level of quiet.

Most recently, Kockelman (1997) investigated the different effects of location on home prices and rents. Measures of land-use patterns, travel-based variables and a variety of dwelling 
units' structural attributes were all included in the model. Changes in accessibility were found to affect total property prices significantly - in both a statistical and practical sense.

This study examines land accessibility from three highly tied perspectives. First, it aims to derive some rent - and thus accessibility - information from models of home valuation. Second, it derives logsum measures of accessibility from destination choice models. Finally, it compares several accessibility measures in the calibration of residential location-choice models.

A possible remedy for some deficiencies associated with conventional measures of accessibility is the use of a utility-based measure, represented by the logsum expression of a logittype discrete choice model. As denoted by Ben-Akiva and Lerman (1985), this technique accounts for the behavioral nature of choice. Niemeier (1997) offered the first application of this technique for the AM journey to work trip. She estimated a multinomial logit model of mode and destination choice, and she used the resulting denominator of the estimated MNL probabilities as measures of mode-destination accessibility. She then converted her mode-destination accessibility to units of dollars and considered changes in alternatives (through removing travel options) by using Small and Rosen's (1981) compensated variation (CV) expression. This is interpreted as the dollar compensation to be given a person in order to make him/her as well off as before a change in environment. Another advantage of this expression is that one can compare accessibility values computed under different model specifications (Niemeier, 1997).

Many residential location models rely on measures of accessibility. One of the earliest approaches, the Lowry model (1964), is based on gravity models of access to basic jobs and population to allocated households and service jobs. More recently, Waddell et al.'s UrbanSim model (2001) makes use of travel-demand model results in location-choice models, in the form of logsum accessibility indices (i.e., expected maximum utilities, using a logit for destination and mode choice).

Alonso (1964) and Mills (1972) have provided continuous monocentric models of household location choice, via utility maximization.

McFadden (1973 and 1978) suggested a new line of thought by using random utility theory and discrete choice models to describe the residence location process. He argued that the choice of residence is made among individual dwelling units, which have a set of characteristics. Individuals react to these attributes by assigning different weights; and subsequently, choose the alternative with the highest utility.

Based on this new theory, Lerman (1977) conducted a study for residence location, auto ownership, and mode to work for single worker households in the Washington, D.C. metropolitan area. He used the multinomial logit (MNL) model to describe the long-run household residence decisions. Each potential residence has transportation network and land use attributes to the household head's workplace, as well as locational attributes, such as shopping opportunities, housing attributes and socioeconomic characteristics.

Sermons and Seredich (2000) included gravity-type measures of employment access in a joint MNL model of residential location and vehicle ownership. They emphasized characteristics of the household for prediction of location preference, but their model restricted the choice set of residence locations to 5 clusters, ignoring the variability within each cluster.

Waddell (1993) challenged the common assumption that a workplace is determined prior to the residence location. He allowed for some interaction between these two variables by using a joint model specification. Furthermore, he argued that the degree to which residence location is driven by workplace location (or the opposite) depends on the degree to which workplace locations are 
dispersed in a city, as well as on individuals' socioeconomic characteristics. One limitation of Waddell's study is that it does not include transit and highway accessibility measures.

Like several of the previous studies discussed here, this study addresses the property valuation problem using hedonic regression models and the location problems using an MNL framework. The data sets include as many zonal and household characteristics as possible, including several measures of accessibility. The surplus valuation of land across zones is used as an estimate of accessibility and then compared to the logsum measures; residential-market behaviors are examined for their linkage to different access measures, suggesting which perform best and thus may best track household preferences and behavior.

\section{MODEL SPECIFICATIONS}

This section describes the structure of the two land use models used in this study: hedonic property pricing models and multinomial logit (MNL) location choice models.

\section{Property Valuation Models}

This study uses hedonic price models (Griliches 1971), which assume that a bundled good's price can be decomposed into its marginal, component parts. Here, the land-price component of a singlefamily home's value is assumed to be a linear function of its accessibility characteristics interacted with its lot size. In other words, each square foot of land is worth marginally more (or less) for marginal changes in any access attribute. Other dwelling unit characteristics make up the improvement component of the total home value. This approach is very similar to Kockelman (1997), and is as follows:

Land Value Component:

$$
\text { Land Value }=\operatorname{Lot} \operatorname{Size}\left(\beta_{0}+\beta_{1} \text { Access }_{1}+\beta_{2} \text { Access }_{2}+\ldots\right)+\varepsilon_{\text {land }}
$$

where Access variables are dependent on different measures of attractiveness (e.g., jobs and parkspace) and different functional specifications (e.g., cumulative opportunities and gravity measures).

Total Property Value:

Property Value $=C+\operatorname{Lot} \operatorname{Size}\left(\beta_{0}+\beta_{1}\right.$ Access $_{1}+\beta_{2}$ Access $\left._{2}+\ldots\right)+\beta_{3}$ HomeAttributes $+\varepsilon_{\text {total }}$ where Home Attributes include variables like the number of bedrooms, age of the structure, and square footage of the structure. Given the relatively simple structure of this model, estimations were done using ordinary least squares (OLS) procedures.

\section{Destination and Residence Location Models}

Ideally, a location choice model captures all factors that contribute to a household's choice of dwelling unit/residence and recognizes the large number of choice alternatives. To limit the size of the choice set, this study relied on aggregated zones as the individual choice alternatives, with average location and structure information. These zones are the traffic analysis processing (TAP) zones used by the North Central Texas Council Of Governments (NCTCOG), which has divided the Dallas-Fort Worth area into 919 TAP zones.

McFadden's MNL model (1973) was used, since location choice may be hypothesized to resemble a utility-maximizing problem on the part of the decision maker with independent and identically Gumbel-distributed random utility components. This model was estimated via likelihood maximization using the Limdep software. But, rather than writing the likelihood function across the 919 alternatives, McFadden (1978) suggested one can randomly sample from among a set of alternatives and use this condensed form to consistently estimate the parameters. To 
ensure a reasonably high level of accuracy, six non-chosen zones were generated for each individual in the destination choice models and nine non-chosen zones were generated for each household in the residence location model. For further details, the reader can refer to Srour (2001).

\section{THE DATA}

This section describes the data used to estimate the property value and location choice models. The property-valuation models are run using observations of specific single-family residential properties; then, the lot-size-normalized residuals of the predictive models are averaged across properties within a single TAP zone, to provide a measure of access valuation (and thus accessibility). In some contrast, the location-choice models are run at the level of specific households, rather than homes, and the zone characteristics have been averaged to provide data for the logit models. More specifics on the data for each of these modeling approaches are described below.

\section{Property Valuation Models}

Table 1's first part defines the variables used in the residential property valuation models. These variables were obtained from two sources: ITC Data Incorporated, which distributes appraisal data for Dallas County, Texas; and the Tarrant Appraisal District (TAD), the property appraisal agency for Tarrant County, Texas.

The Dallas County data set purchased from ITC Data Inc. consists of two separate files, one with characteristics of 630,105 residential properties and one with characteristics of 25,859 commercial properties, corresponding to the year 2001 appraisal period. Information available for the residential properties included land value, improvement value, land size, improvement size, number of bathrooms, number of garage bays, and year built. Information available for the commercial properties included land value, land size, improvement type, improvement value, improvement size, number of garage bays, and year built.

The TAD website provides several files with data from the 2001 appraisal period. Containing over 539,030 addresses, the file was condensed to include only single-family residential properties. Information available for each of the remaining 374,642 addresses included land value, improvement value, land size, improvement size, number of bathrooms, number of garage bays, and year built.

Using TransCAD Caliper 4.0, the addresses of both Dallas and Tarrant county properties were mapped onto a GIS file and overlaid with a map of TAP zones for the Dallas-Fort Worth region. After matching addresses to their correct zones, observations that were not matched to a TAP zone were filtered out of the database. Next, samples lacking land value, land size, improvement value, or improvement size were removed. To account for possible errors in the data, any address with land value less than \$20,000, land size less than 300 square feet, age over 200 years, number of garage bays greater than 10 , and/or number of bathrooms higher than 10 was removed, leaving a final data set with 697,695 observations.

Some traditional accessibility measures were added to the data set. These include the network distance to both the Dallas and Fort Worth CBDs (in miles, and interacted with the lot size, in square feet). In addition, a set of accessibility measures that were computed under a research project concurrently underway at the University of Texas at Austin and sponsored by the Texas Department of Transportation was added to the data set. These include cumulative opportunity measures for three types of activities: shopping, social-recreational, and work trips. The measures of attractiveness are park space, total employment, and retail employment. The result is three 
different accessibility indices for each of the TAP zones. The functional form for the accessibility of a zone $i$, located in an area with $j$ zones, is shown below:

$\operatorname{Access}_{\mathrm{CO}, i}=\sum_{j}^{J}$ Attractiveness $_{j}$ s.t. $t_{i j} \leq 30 \mathrm{~min}$.

A similar data set was obtained at the census tract level from the North Central Texas Council of Governments (NCTCOG) website. The research and information services department at NCTCOG provides several census of population-based files with data from the 1990 appraisal period. These come from the 1990 Census of Population, which requests households' selfappraisals of home value. Information available for each of the 897 census tracts included the following list of variables, estimated for single-family residences: number of housing units by value of improvement, housing units by square footage of improvement, housing units by number of bedrooms, housing units by number of rooms, and housing units by year built.

Average home size, property value, age, number of bedrooms, and number of rooms were calculated for the 897 census tracts included in the Dallas-Fort Worth Metroplex (using a weighted average of characteristics). A key variable that was missing at this stage was average lot sizes; not provided by the NCTCOG. Average lot sizes per census tracts were estimated using a weighted formula suggested by Kockelman (1997) by dividing the census block total area by the equivalent number of single detached dwelling units. The latter was computed by estimating the relative footprint sizes of moderate-and high-density dwelling units as a percentage of the single detached dwelling unit footprint.

106 records with missing information on one or more explanatory variables were removed from the data set reducing its size to 791 census tracts.

\section{Destination Choice Models}

A sample of individual trip making was obtained from Dallas-Fort Worth's 1996 Household Travel and Activity Diaries Survey, as provided by the NCTCOG. The survey consisted of a questionnaire filled out by 10,607 individuals living in the Dallas-Fort Worth Metroplex. The results consist of a set of individual and household attributes in addition to information about 119,443 trips made by the surveyed individuals.

The land use information for these models was obtained from two sources. First, the NCTCOG provided land use coverage data by TAP, including characteristics such as zone size, park space, employment (by major industrial category), and population density. NCTCOG also provided estimates of peak-hour travel time and cost data between pairs of TAP zones by the highway mode. The preparation of the data set for estimation was performed by Hui-min Zhao as part of a research study at the University of Texas at Austin. Missing records were removed from the data set. Subsequent to this process, three sets of activities were selected: work-related, socialrecreational, and shopping-related. The results are 4561 records for the first trip purpose, 1817 for the second, and 1206 for the third.

\section{Residence Location Model}

A sample of household characteristics and home locations was obtained from the previously described Household Travel and Activity Diaries Survey. Data assembly required preparing several sets of files, one with household characteristics, another with household head characteristics, and a third containing zonal attributes.

The term "household head" was not used in the original travel/activity-survey data set. Here, we assume it is the individual who is likely to make the residence location decision, and we 
consider his/her demographic characteristics for the residence location choice model. This study assigned three criteria for the identification of the household head, based on the following attributes in descending order of importance: income, age, and gender. For each household, the individual with the highest income level was considered to be the household head. For cases of more than one person in the highest income category, age was considered; the older individual was chosen to be the head. Finally, in the cases where two persons had the same high income and the same (high) age (this was done for 193 households), the male was considered as the head.

After cleaning the data, the resulting records were examined for comparability with the original data set. Absolute differences in vehicle ownership, household size, number of children, and household income bracket differed by less than 6 percent. However, the number of workers differed dramatically: the sample averaged 1.55 workers, while the original data averaged only 1.21. This is because only households with workers were kept; thus, 1115 households (with zero workers) were removed from the original data set, biasing this final value upwards.

\section{RESULTS AND ANALYSIS}

This section presents the estimated coefficients and suggested interpretations for the three types of land use models: residential property valuation, destination choice, and residence location.

\section{Property Valuation Models}

Table 2 presents the result of three property-valuation models. The first one was estimated using residential property characteristics at the parcel level, the second was estimated using residential property characteristics at the census tract level, and the third was estimated using commercial property attributes.

Since property valuations are difficult data to obtain, but accessibility indices provide valuable measures of land use-transport provision for neighborhoods and groups of interest (e.g., the elderly or poor), one may wish to combine various accessibility indices (based on relatively available land use and travel time data) to create a more comprehensive estimate of accessibility, tied to land values (i.e., households' willingness to pay for location). Thus, one could examine the multivariate relation between land value and various accessibility indices. This is effectively done in Table 2's models, where accessibility indices were added for explanatory power.

Table 2's first model expresses total property valuation as the sum of land valuation, where lot size is interacted with three accessibility measures and improvement characteristics. The signs and magnitudes on the accessibility-related coefficients (all based on cumulative opportunities) suggest that work accessibility adds the most to the price of a parcel of land, whereas shopping accessibility actually detracts. The standardized coefficients (not shown here) on the work accessibility (all job types) measure is +0.291 , indicating that the model estimates every 1 standard deviation (SD) rise in this variable to contribute to a rise in the response variable (total property value) that is $29 \%$ of its SD. This is very practically significant. In contrast, the standardized coefficient associated with park space accessibility is just -0.246 , and that of shopping (retail jobs) accessibility is 0.044 .

One should be careful interpreting the signs of the un-standardized coefficients on both distances to Dallas and Fort Worth CBDs. Rather than implying that properties in zones close to both CBDs are less valuable than those in farther zones, the signs reflect multi co-linearity effects between the distances to both CBDs and the set of cumulative measures of accessibility. Removal of the $\mathrm{CO}$ access measures results in negative signs on these distance variables. 
A similar interpretation may be given for the fact that the number of garage bays has a negative un-standardized coefficient $(-\$ 2,546)$. The negative sign may imply that properties that are far from both CBDs, and thus are less accessible, have more garage bays than others.

As expected, the number of bathrooms adds substantially (\$30,820 each), and improvement size adds significantly ( $\$ 106.3$ per square foot). The age of the structure, interacted with structure size, is also significantly negative. In terms of standardized coefficients (not shown here), improvement size has the biggest effect $(+0.667)$, as one might have expected.

The coefficients obtained from this hedonic model of residential property value were used to estimate land value residuals, which are as a proxy for accessibility. Land residuals were calculated by subtracting the estimated average property value per each property from the observed one. Then, the obtained terms were divided by the average lot size per census tract to give an estimate of average urban accessibility (per square foot) per property. The new measures were then aggregated to the TAP zones-level and normalized on a linear scale from 1 to 100 .

Figure 1's first map presents the obtained average land value residual-values ${ }^{1}$ per TAP zone in the Dallas-Fort Worth Metroplex. The most accessible zones are those located to the north of Dallas CBD. Areas close and to the north of Fort Worth CBD are more accessible than others in Tarrant County. Zones in the south of Dallas County and zones in the east of Tarrant County are generally less accessible than others.

Table 2's second model presents a hedonic land price model, obtained from the census tractlevel data set. The signs and magnitudes on the different property characteristics suggest that the number of bedrooms adds more to the price of a parcel of land than other room-types. The standardized coefficients on the number of bedrooms is +0.530 , indicating that the model estimates every 1 standard deviation (SD) rise in this variable to contribute to a 53\%-of-SD rise in the response variable (property value). This is very practically significant. In contrast, the standardized coefficient associated with number of rooms is just 0.120. Furthermore, each additional bedroom is worth $\$ 97,742$ (=\$ $89590+\$ 8152$ ), whereas each additional room (non-bedroom) is worth $\$ 8152$ only. Finally, each additional square foot of land adds $\$ 1.450$ to the total property value, on average.

Figure 1's second map presents average census-based land value residual-values obtained per TAP zone. The most valued land lies in zones located close to and north of the Dallas CBD. Land in zones close to and west of the Fort Worth CBD is more valued than others in Tarrant County.

Finally, Table 2's third model presents a hedonic land price model, obtained from the commercial property data set. The signs and magnitudes on the different property characteristics suggest that building size adds the most to the price of a commercial parcel of land. The standardized coefficient on the building size is +0.994 , indicating that the model estimates every 1 standard deviation (SD) rise in this variable to contribute to a $94.4 \%$ rise in the response variable's (property value) SD. Furthermore, the signs on accessibility coefficients indicate that high-value commercial properties are located in areas highly accessible to shopping facilities rather than to parkspace. In contrast, the negative sign on the number of population within 30 minutes indicates that highly accessible commercial areas are less populated than others (in terms of residential population), which is due to the fact that those areas are generally located in the CBD as suggested by Figure 1's third map.

\section{Destination Choice Models}


Table 1's second part presents the explanatory variables used in the destination choice models presented in table 3. Table 3's first model presents the estimation results of the different coefficients of the work-related destination choice MNL model after eliminating all statistically insignificant variables ( $\mathrm{t}$-values < 1.6). As expected, the coefficients of the number of jobs in the three considered sectors were estimated to be positive (and highly statistically significant) indicating that a zone's attraction for work trips increases with the level of employment. The coefficients on the industrial and office acreage came out to be positive. However, negative coefficients were estimated for park space and parking areas indicating that zones with high levels of these two variables generally attract fewer work-related trips than others. Employment is generally centered in the CBD areas where parking areas are limited and where park space areas are "practically" non-existent.

As expected, the coefficient on the in-vehicle travel time (IVTT) was estimated to be negative whereas the out-of-vehicle travel time was positive, suggesting that zones that are chosen for work purposes are served by transit systems.

Table 3's second presents the estimation results for the social-recreational destination choice MNL model. The coefficients on the number of retail jobs and some land-area measures such as offices, institutions, and park space, were estimated to be positive indicating that a zone's attraction for social-recreational trips increases with the levels of these variables. In contrast, a negative sign was obtained on the industrial-area variable indicating that industrial zones are less attractive for this trip-type.

As expected, the coefficient on the in-vehicle travel time and the travel cost were estimated to be negative, whereas the parking cost coefficient was positive, indicating that zones that are chosen for social-recreational trips may have high parking cost.

Table 3's third model presents the estimation results for the shopping destination location choice MNL model. As expected, the coefficients on the number of jobs in the retail and service sectors were estimated to be positive (and highly statistically significant) indicating that a zone's attraction to shopping trips increases with the level of employment opportunity in the retail and service sectors. The coefficients on the different size measures such as institutions and parking areas were positive. However, a negative coefficient was estimated for airport areas indicating that zones with airport facilities do not generally include many shopping malls. Those zones are generally empty for aviation safety and noise pollution considerations. As expected, the coefficients on the in-vehicle and out-of-vehicle travel times were estimated to be negative.

The estimated coefficients were used to determine the systematic utility of the 919 TAP zones for three trip types: work, social-recreational, and shopping. Subsequently, the exponential terms of these utilities were summed for the 919 origin zones. The natural logarithm of each originspecific sum was considered as access measures for a certain trip-type. These were then normalized on a linear scale from 1 to 100 .

Similar distributions of access measures in the Dallas-fort Worth Metroplex were obtained for the three trip purposes. Figure 1's fourth, fifth, and sixth maps present the computed measures for work, recreational, and shopping trips respectively. As expected, zones in the Dallas CBD have the highest accessibility, whereas zones in the Fort Worth CBD exhibit higher access than other areas in Tarrant County. Zones in Dallas County have more accessibility than those in Tarrant County. Finally, accessibility generally falls with an increase in the distance from both CBDs.

These values of access have been correlated with the land value residuals obtained from the property valuation models, with results shown in Table 4 . The three logsum measures were highly correlated indicating that zones that are highly accessible for work trips are also highly accessible 
for shopping and social-recreational trips and vice-versa. As discussed in the previous chapter, zones close to either one of the two CBDs generally have high accessibility for work, shopping, and social-recreational trips. Conversely, the land value residuals computed using the property valuation models had statistically insignificant negative correlation coefficients (less than 0.2 in absolute value) with the three logsum measures, indicating that the two sets of measures are capturing different effects. Based on trip destination choices, the logsum measures describe the accessibility of an area as its expected maximum utility for the considered trip purpose. They require that exactly one trip will be taken and are conditional on this behavior by virtue of their data and specification. In contrast, the land value residuals are much less clearly defined. Computed using the valuation residuals of hedonic models, those measures include many latent factors in the model specification such as school quality, crime levels, and air pollution. Moreover, land value residuals obtained at the parcel level were distributed in only 600 TAP zones of the 919-zone Metroplex.

\section{Residence Location Models}

The explanatory variables used in residential location choice model are the distance to work zone, average property attributes, distance to the Dallas CBD, distance to the Fort Worth CBD, and a set of other accessibility measures. Four types of accessibility measures were tried, and the best functional specification (i.e., the one with the highest statistical significance and reasonable behavioral interpretation) was selected.

Table 5 presents four residence location models. The first one includes measures of job, parkspace, and shopping accessibility obtained from the three destination choice models, whereas the second model includes the same type of access measures expressed as cumulative opportunities. The last two models use residential land values residuals obtained from the property valuation model estimated at the parcel-level and at the census tract-level respectively. As expected, the coefficient on the distance-to-household head's work location was estimated to be negative (and highly statistically significant) indicating that a zone's attraction to a household falls as commute distance increases.

The resulting estimates emphasize the selection of the second model since it both enjoys the highest statistical significance (highest adjusted rho-square value) and allows for an intuitive interpretation of the effect of accessibility on residence location. The estimated negative coefficient on both recreational and shopping accessibility suggests that households value access to jobs more than they value access to other opportunities. Here again, it is important to note that these land residuals include many zonal un-observed factors in the model specification such as: school rating, crime rating, and air pollution, along with land accessibility.

\section{CONCLUSIONS}

This study uses location accessibility as a major explanatory variable for property-valuation and residential location modeling. Access to jobs, retail employment, and parkspace were found to be statistically and practically significant in both model types. They also exhibit relations of interest with land rent estimates, which are computed based on normalized residuals of property-valuation models. Such a connection has not been made so explicit before, and it suggests that rent formulations may prove a valuable measure of access, since they track consumers' willingness to pay for location. The access may be to jobs, retail centers, parks, good schools, views, or other amenities; it is all capitalized into rent through market bidding.

More research in this area should further illuminate such relationships. And applications in other locations and to other land uses would be valuable. Other location characteristics could be 
added to the property valuation and location choice models such as school ratings, air quality, racial composition, and tax rates; accessibility could be assessed using other modes of transportation; and movers (rather than existing home owners) could offer more timely data on the nature of location choice. Finally, more reliable interzonal travel times and assessed valuation data sources should be considered. The negative correlation between the appraisal-based accessibility and the logsum measures could be due to some errors in the datasets and/or to the issue of spatial aggregation, since the land value residuals were aggregated to the level of TAP zones.

The ability of the models to suggest which functional specifications of accessibility are best (disaggregated by demographics) is very valuable for policy-making and evaluation of land use and travel network trends. Job accessibility proved to exert the most positive effects on home valuation and location choice here. Cumulative opportunities measures of accessibility had the highest explanatory power in a residence location model. These and other results obtained here offer valuable methods for assessing impacts of accessibility changes across demographic sub-groups. Nations, states, and regions are interested in knowing which measures of accessibility are best - and for which purposes. This work provides some answers - and offers new directions.

\section{ACKNOWLEDGEMENTS}

The authors are grateful to all those who provided help throughout the development of this study. These include TAD's John Hunt for his help in the acquisition of the property value data for Tarrant County; Chandra Bhat for providing NCTCOG's activity surveys, land use information, and travel cost data sets; and the Texas Department of Transportation and National Science Foundation for their financial support of this effort.

\section{ENDNOTES}

${ }^{1}$ The map shows zones for all or part of nine of the Dallas-Fort Worth area counties, but only Dallas and Tarrant Counties offer appraisal data. The others do, however, offer location choice data and are therefore shown here for purposes of illustration. 


\section{REFERENCES}

1. Leake, G.G. and Huzayyin, A.S. 1979. "Accessibility Measures and Their Suitability for Use in Trip Generation Models." Traffic Engineering and Control. Vol. 2 (December): 566572.

2. Wachs, M. and T.G. Kumagi 1973. "Physical Accessibility as a Social Indicator." SocioEconomic Planning Science. Vol. 7: 437-456.

3. Ben-Akiva, M. and S. R. Lerman. 1985. Discrete Choice Analysis: Theory and Application to Travel Demand. The MIT Press, Cambridge.

4. Niemeier, D.A. 1997. "Accessibility: An Evaluation Using Consumer Welfare." Transportation. Vol. 24: 377-396.

5. Small, K. and S. Rosen. 1981. "Applied Welfare Economics with Discrete Choice Model". Econometrica. Vol. 49: 105-130.

6. Kockelman, Kara. 1997. "The Effects of Location Elements on Home Purchase Prices and Rents." Transportation Research Record. No. 1606: 40-50.

7. Mohring, Herbert. 1961. "Land Values and the Measurement of Highway Benefits." Journal of Political Economy. Vol. 49 (June): 236-249.

8. Anas, Alex. 1979. Residential Location Markets and Urban Transportation. New York: Academic Press.

9. Voith, Richard. 1991. "Transportation, Sorting and House Values.” AREUEA Journal. Vol. 19, No.2: 117-137.

10. McMillan, Melville L., Bradford G. Reid, and David W. Gillen. 1980. "An Extension of the Hedonic Approach for Estimating the Value of Quiet." Land Economics. Vol. 56, No. 3 (August): 315-328.

11. Lowry, Ira. 1964. A Model of Metropolis. RM-4035-RC, The Rand Corporation, Santa Monica, CA.

12. Waddell. P., A. Borning, M. Noth, N. Freier, M. Becke, and G. Ulfarsson. 2001. UrbanSim: A Simulation System for Land Use and Transportation, 2001. (Accessed on 05/15/2001 at 16:00 GMT at the UrbanSim Website: http://www.urbansim.org/Papers/UrbanSim_NSE_Paper.pdf)

13. Alonso, William. 1964. Location and Land Use. Cambridge: Harvard University Press.

14. Mills, E. S. 1972. Studies in the Structure of Urban Economy. Baltimore: John Hopkins.

15. McFadden, Daniel. 1973. Conditional Logit Analysis of Qualitative Choice Behavior. In Frontiers in Econometrics, edited by Paul Zarembka. Academic Press, New York.

16. McFadden, Daniel. 1978. Modeling the Choice of Residential Location. In Spatial Interaction Theory and Planning Models, edited by A. Karlqvist et al. Amsterdam: North Holland Publishers.

17. Lerman, Steven. 1977. "Location, Housing, Automobile Ownership, and Mode to Work: A Joint Choice Model." Transportation Research Record. No 610: 6-11.

18. Sermons, William and Natalya Seredich. 2001. "Assessing Traveler Responsiveness to Land and Location Based Accessibility and Mobility Solutions." Transportation Research Part D6: 417-428.

19. Waddell, Paul. 1993. "Exogenous Workplace Choice in Residential Location Models: Is the Assumption Valid?" Geographical Analysis, Vol. 25, No. 1: 65-82.

20. Griliches, Z. (Ed.) 1971. Price Indices and Quality Changes Studies in New Methods of Measurements. Cambridge, Mass.: Harvard University Press. 
21. Srour, I. 2001. The Derivation of Accessibility Indices from Property Valuation and Destination Choice Models and Their Use in Residence Location Models. Master Thesis Report, The University of Texas at Austin. 
Figure 1. Maps of the Dallas-Fort Worth Metroplex Showing the Average Normalized LandValue Residuals - Estimated Using Property Value Models and Average Normalized Accessibility Measures Estimated Using Destination Choice Models for Work, Social-Recreational, and Shopping Trips

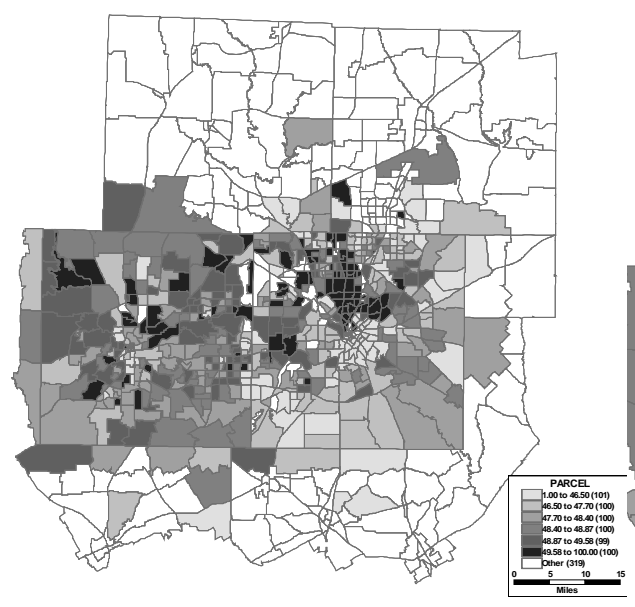

Parcel-Level Residential Data

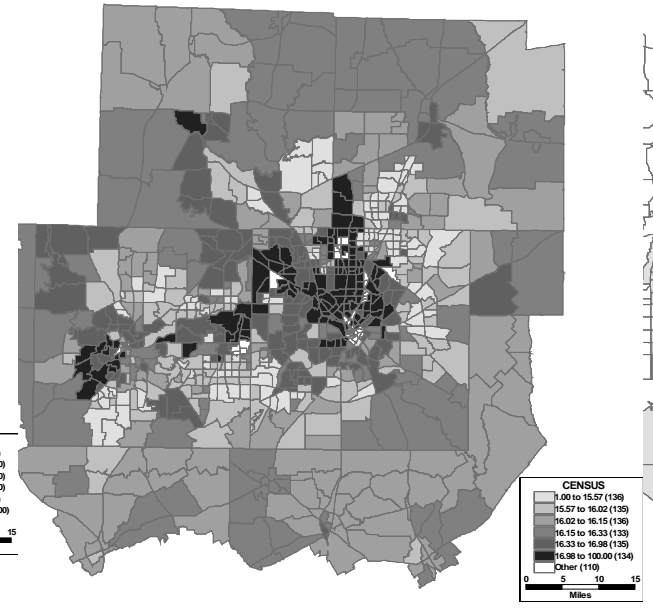

Census Tract-Level Residential Data

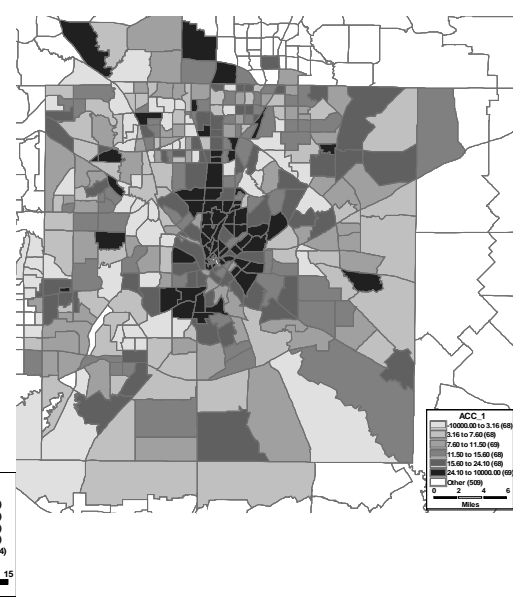

Parcel-Level Commercial Data (Dallas County Only)

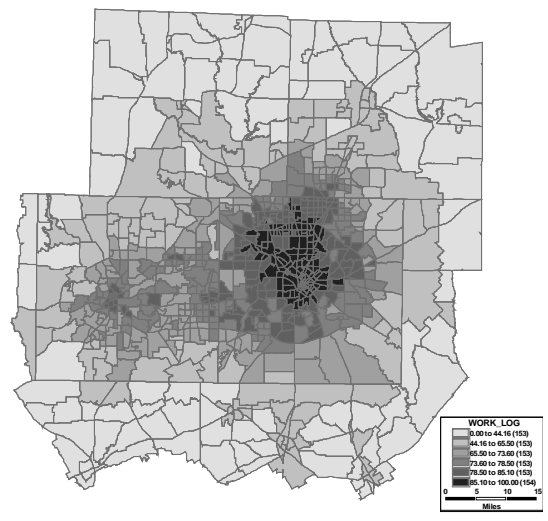

Work

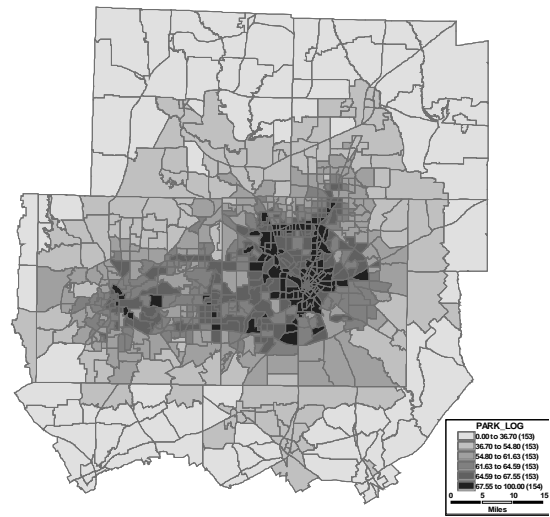

Social-Recreational

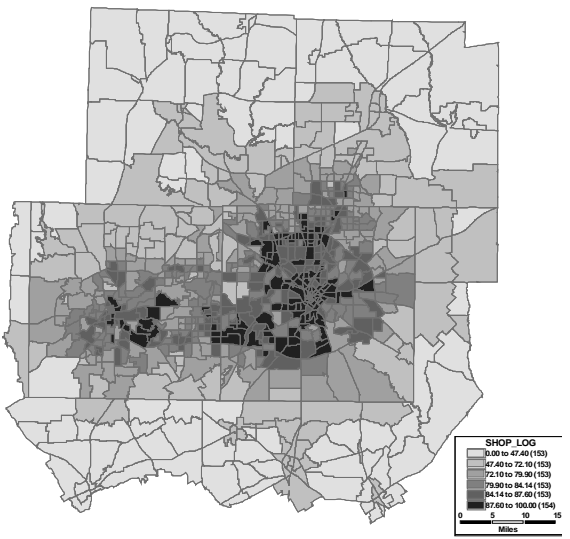

Shopping 
Table 1. Description of Variables

\begin{tabular}{|c|c|c|c|}
\hline \multicolumn{2}{|c|}{ Property Valuation Models } & \multicolumn{2}{|c|}{ Destination and Residence Location Models } \\
\hline Variable Name & Description & Variable Name & Description \\
\hline Lot Size & Lot Size in Square Feet (SF) & Ln(BasicEmpl) & $\begin{array}{l}\text { Number of Jobs in the Basic } \\
\text { Employment Category }\end{array}$ \\
\hline DU Size & DU Size in SF & Ln(RetailEmpl) & $\begin{array}{l}\text { Number of Jobs in the Retail } \\
\text { Employment Category }\end{array}$ \\
\hline DU x Age & DU Size in SF $x$ DU Age & Ln(ServiceEmpl) & $\begin{array}{c}\text { Number of Jobs in the Service } \\
\text { Employment Category }\end{array}$ \\
\hline DU x Age ${ }^{2}$ & DU Size in SF $x(\text { DU Age })^{2}$ & $\operatorname{Ln}($ Acreage $)$ & $\begin{array}{c}\text { Total Area of a TAP Zone } \\
\text { (acres) }\end{array}$ \\
\hline Garage Stalls & Number of Garage bays/DU & $\operatorname{Ln}$ (Airport) & Airports Areas (acres) \\
\hline Rooms & Number of Rooms/DU & Ln(Hotels/Motels) & Hotels and Motels Areas (acres) \\
\hline Bedrooms & Number of Bedrooms/DU & Ln(Industrial) & $\begin{array}{c}\text { Manufacturing, Offices, and } \\
\text { Warehouses (acres) }\end{array}$ \\
\hline Bathrooms & Number of Bathrooms/DU & Ln(Institutions) & $\begin{array}{c}\text { Churches, Museums, and } \\
\text { Schools (acres) }\end{array}$ \\
\hline Dallas Index & $\begin{array}{c}\text { Binary variable indicating if a zone } \\
\text { is within Dallas County }\end{array}$ & $\operatorname{Ln}($ Park space $)$ & $\begin{array}{c}\text { Public and Private Parks, Golf } \\
\text { Courses (acres) }\end{array}$ \\
\hline $\begin{array}{l}\text { LS x } \\
\text { CRDDallas }\end{array}$ & Distance in miles from the & Ln(Parking) & CBD Parking and Lots \\
\hline CBDDallas & $\begin{array}{c}\text { considered property to Dallas CBD } \\
\text { Distance in miles from the }\end{array}$ & & \\
\hline LS x CBDFW & $\begin{array}{c}\text { considered property to Fort Worth } \\
\text { CBD }\end{array}$ & Ln(Water) & Lakes (acres) \\
\hline $\begin{array}{c}\text { LS x } \\
\text { AllEmplCOAI }\end{array}$ & $\begin{array}{l}\text { Lot Size x Sum of available jobs } \\
\text { within } 30 \text { min of travel time from } \\
\text { the considered TAP zone }\end{array}$ & Travel Cost & $\begin{array}{l}\text { Estimated fuel cost (1996 US } \\
\text { Dollars) }\end{array}$ \\
\hline LS x ParkCOAI & $\begin{array}{c}\text { Lot Size x Sum of park-space } \\
\text { acreage within } 30 \text { min of travel } \\
\text { time from the considered TAP zone }\end{array}$ & IVTT & $\begin{array}{l}\text { Average In-Vehicle Travel } \\
\text { Time (minutes) }\end{array}$ \\
\hline $\begin{array}{c}\text { LS x } \\
\text { ShopCOAI }\end{array}$ & $\begin{array}{c}\text { Lot Size } \times \text { Sum of retail jobs within } \\
30 \text { min of travel time from the } \\
\text { considered TAP zone }\end{array}$ & OVTT & $\begin{array}{c}\text { Average Out-of-Vehicle Travel } \\
\text { Time (minutes) }\end{array}$ \\
\hline LS x PopCOAI & $\begin{array}{c}\text { Lot Size x Population within } 30 \\
\text { min of travel time from the } \\
\text { considered TAP zone }\end{array}$ & Parking Cost & Parking Cost (1996 US Dollars) \\
\hline
\end{tabular}

DU $=$ Dwelling Unit, COAI $=$ Cumulative Opportunities Accessibility Index

Note: All distances and travel times are on the network from the considered property, under peakhour conditions. 
Table 2. Property Value Regressions

\begin{tabular}{|c|c|c|c|}
\hline Variable Description & Parcel-Level Residential & $\begin{array}{c}\text { Census-Level } \\
\text { Residential } \\
\end{array}$ & $\begin{array}{l}\text { Parcel-Level } \\
\text { Commercial } \\
\end{array}$ \\
\hline Constant & $-139,100(-381)$ & $-220,500(-14.7)$ & $-330,534(-17.2)$ \\
\hline Lot Size $\left(\mathrm{ft}^{2}\right)$ & $0.276(7.46)$ & $1.450(2.53)$ & $-0.920(-2.00)$ \\
\hline DU Size $\left(\mathrm{ft}^{2}\right)$ & $106.3(532)$ & & $64.83(139)$ \\
\hline Bedrooms & & $89590(14.3)$ & \\
\hline Rooms & & $8152(3.49)$ & \\
\hline Garage Stalls & $-2546(-21.3)$ & & \\
\hline Bathrooms & $30820(138)$ & & \\
\hline DU x Age & $-0.8850(-110)$ & $-9.509 \mathrm{E}-02(-3.16)$ & $-0.379(-25.8)$ \\
\hline DU x Age ${ }^{2}$ & $1.940 \mathrm{E}-02(173)$ & $1.106 \mathrm{E}-03(2.61)$ & \\
\hline Dallas Index & $26870(104)$ & & \\
\hline LS x CBDDallas & $1.258 \mathrm{E}-02(18.5)$ & $9.123 \mathrm{E}-03$ (1.72) & $-5.030 \mathrm{E}-02(-3.57)$ \\
\hline LS x CBDFW & $-2.617 \mathrm{E}-02(-57.4)$ & $-1.361 \mathrm{E}-04(-0.04)$ & 4.952E-02 (8.96) \\
\hline LS x AllEmplCOUAI & 4.378E-02 (48.6) & $6.328 \mathrm{E}-02(5.49)$ & $6.714 \mathrm{E}-03(0.76)$ \\
\hline LS x ParkCOUAI & $-3.010 \mathrm{E}-02(-64.6)$ & $-1.848 \mathrm{E}-02(-4.04)$ & $-1.940 \mathrm{E}-02(-3.89)$ \\
\hline LS x ShopCOUAI & $6.377 \mathrm{E}-03(5.80)$ & $-1.253 \mathrm{E}-02(-0.939)$ & $5.096 \mathrm{E}-02(4.44)$ \\
\hline LS x PopCOUAI & & & $-1.440 \mathrm{E}-06(-2.78)$ \\
\hline Adjusted R-Squared & 0.635 & 0.550 & 0.662 \\
\hline Nobs & 697,695 & 809 & 25,859 \\
\hline
\end{tabular}

Final models based on statistical significance

t-values are shown in parentheses 
Table 3: Destination Choice Models for Three Trip Purposes

\begin{tabular}{|c|c|c|c|}
\hline Variable Description & Work & Recreational & Shopping \\
\hline \multicolumn{4}{|l|}{ Level of Employment } \\
\hline Ln(BasicEmpl) & $3.510 \mathrm{E}-02(5.23)$ & & \\
\hline Ln(RetailEmpl) & $5.140 \mathrm{E}-02(3.13)$ & $0.2361(9.38)$ & $0.2526(6.61)$ \\
\hline Ln(ServiceEmpl) & $0.4215(18.3)$ & & 6.880E-02 (1.64) \\
\hline \multicolumn{4}{|l|}{ Area by Land Use Type } \\
\hline Ln(Acreage) & $0.1446(6.18)$ & $0.2242(6.30)$ & $0.3962(8.41)$ \\
\hline Ln(Airport) & & & $-2.520 \mathrm{E}-02(-2.36)$ \\
\hline Ln(Industrial) & $1.560 \mathrm{E}-02(4.82)$ & $-2.100 \mathrm{E}-02(-2.93)$ & \\
\hline Ln(Institutions) & & $5.470 \mathrm{E}-02(5.06)$ & 4.770E-02 (4.65) \\
\hline Ln(Offices) & $2.040 \mathrm{E}-02(5.97)$ & $1.520 \mathrm{E}-02(1.97)$ & \\
\hline Ln(Park space $)$ & $-1.250 \mathrm{E}-02(-3.17)$ & $1.650 \mathrm{E}-02(2.17)$ & \\
\hline Ln(Parking) & $-2.020 \mathrm{E}-02(-1.76)$ & & $6.410 \mathrm{E}-02(3.41)$ \\
\hline Ln(Water) & $9.14 \mathrm{E}-03(2.25)$ & & \\
\hline Level of service: & & & \\
\hline IVTT & $-0.1000(-52.2)$ & $-9.040 \mathrm{E}-02(-34.4)$ & $-0.1173(-29.2)$ \\
\hline OVTT & $0.1206(4.00)$ & & $-0.2793(-2.97)$ \\
\hline Cost & 2.500E-03 (2.20) & $-8.850 \mathrm{E}-03(-3.82)$ & \\
\hline Parking Cost & & $5.600 \mathrm{E}-03(3.07)$ & \\
\hline Log-Likelihood Ratio & -4519 & -2022 & -1003 \\
\hline Adjusted Rho-Squared & .4908 & 0.4281 & .5722 \\
\hline Nobs & 4,561 & 1,817 & 1,206 \\
\hline
\end{tabular}

Final models based on statistical significance

$\mathrm{t}$-values are shown in parentheses 
Table 4: Correlation of Accessibility Measures

\begin{tabular}{|r|ccc|cccc|cc|ccc||}
\hline & \multicolumn{2}{|c|}{$\begin{array}{l}\text { Logsum } \\
\text { AllEmpl }\end{array}$} & $\begin{array}{l}\text { Logsum } \\
\text { Park }\end{array}$ & Shogsum & $\begin{array}{c}\text { CO } \\
\text { AllEmpl }\end{array}$ & $\begin{array}{c}\text { CO } \\
\text { Park }\end{array}$ & $\begin{array}{c}\text { CO } \\
\text { Shop }\end{array}$ & $\begin{array}{c}\text { CO } \\
\text { Pop }\end{array}$ & $\begin{array}{c}\text { CBD } \\
\text { Dallas }\end{array}$ & $\begin{array}{c}\text { CBD } \\
\text { FW }\end{array}$ & \multicolumn{3}{|c|}{ Land Residuals } \\
Parcel Census Commercial||
\end{tabular}


Table 5. Residence Location MNL Models

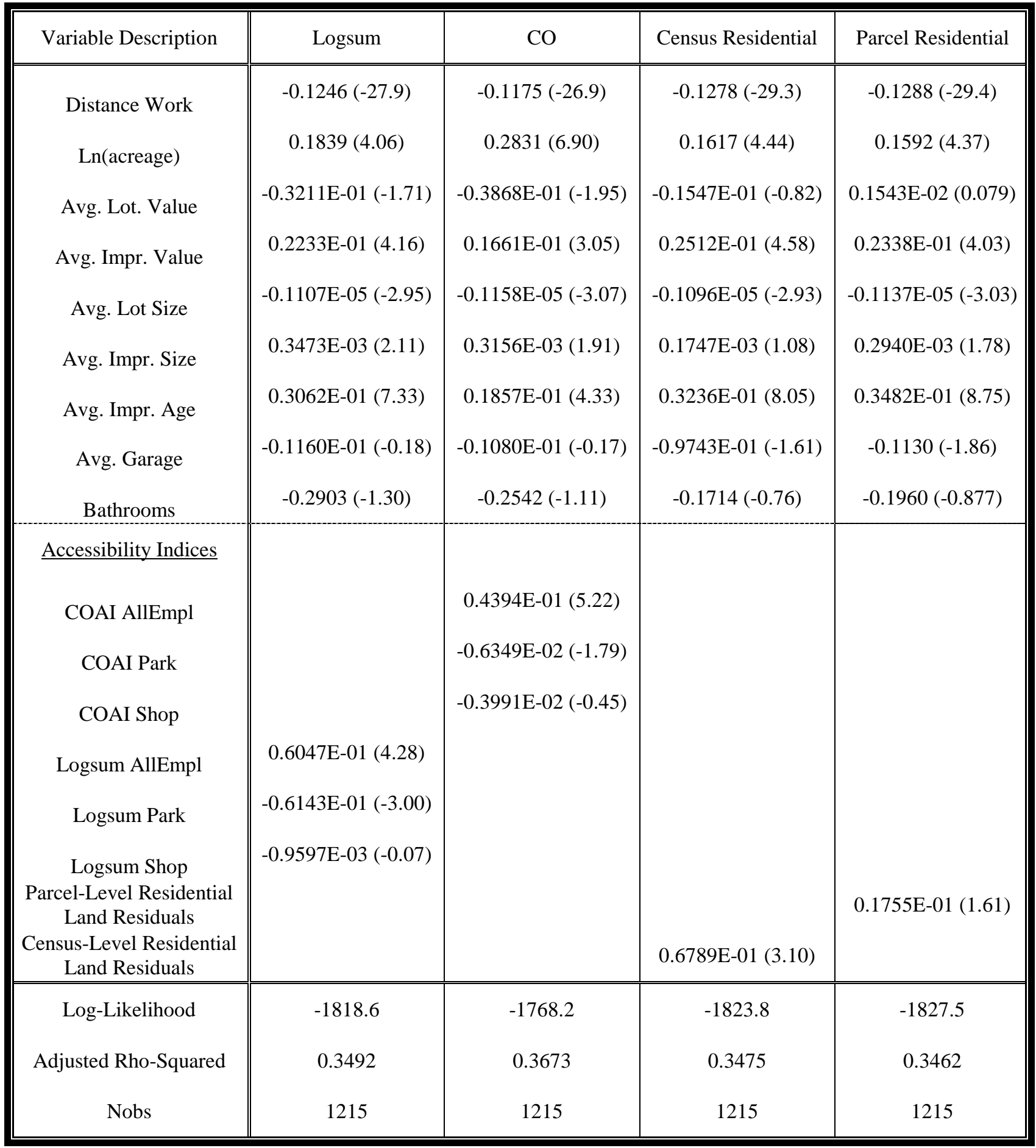

t-values are shown in parentheses 